\title{
Effect of Health Education Program on Knowledge and Practice of Workers Regarding Occupational
} Health Hazards at Sugar Factory

\author{
Adel Ali Abdelwahab', Soheir Ali Bader EL-Din², Awatef Abd.El.razek Mohammed ${ }^{3}$
}

\author{
1. Assistant lecturer of Community Health Nursing, Faculty of Nursing, Minia University, Egypt. \\ 2. Professor of Community Health Nursing, Faculty of Nursing, Cairo University, Egypt. \\ 3. Professor of Community Health Nursing, Faculty of Nursing, Minia University, Egypt
}

\begin{abstract}
Background: The workers are exposed to workplace hazards arising from various activities involved in sugar production. Aim: study aims to assess effect of health education program on knowledge and practice of workers regarding occupational health hazards at sugar factory. Design: Quasi-experimental design was utilized for this study with pre/posttest. Sample: A purposive sample with number of 130 workers according to specific criteria. Setting: The present study was carried out in Minia sugar factory in Abu Korkas district, Tools: Data were collected using three tools; the first tool included questions related to demographic characteristics, health history, health habit and occupational health services. The second tool is a questionnaire regarding knowledge of workers about occupational health hazards and the third tool is a self-reported practice questionnaire about using workers personal protective equipment and most commonly first aid in the factory. Results: the mean age was $44.7 \pm 8.7$, 37.7\% years. All workers of the study sample had poor knowledge about occupational health hazards and unsatisfactory self-reported practice regarding personal protective equipment and first aids. Conclusion: post implementation of health education program the workers knowledge and self-reported practice improved. Recommendation: on-site training programs for workers have to be implemented to improve their working skills. Training programs should include awareness about safety measures and orientation regarding work hazards and how to avoid work related injuries as well as first aid measures.
\end{abstract}

Key words: sugar factory, hazards, education program, PPE and first aids.

steam used to drive turbines, burgusse fires in the dry season and gases from the lagoons which can cause skin diseases. There was no facility for the workers to drink clean and pour water, lubricant dropped on the passage of the workers, there was no facility of first-aid and preventive maintenance staff was no appointed at the sensitive sections of sugar mills. (Hamza, 2016)

\section{Significant of study:}

The global burden of diseases associated with occupational factors was estimated as 4-10 million cases per year, with approximately 3-9 million in several developing countries per year. The international labor association (ILO), the United Nations agency, has estimated that industrial workers, on a global scale suffer around hundred and sixty million occupational diseases and two million deaths per year, fatalities due to respiratory diseases represent around 140,000 of these. An estimated $12 \%$ of chronic obstructive respiratory diseases deaths are from occupational exposure to airborne particulates. (Ahmad, Sattar, \& Nawaz, 2016)

Sugar cane workers have a high level of occupational accidents and are exposed to the high toxicity of pesticides. They may also have an increased risk of lung cancer, possibly mesothelioma. This may be related to the practice of burning foliage at the time of cane-cutting. Bagassosis is also a problem specific to the industry as it may follow exposure to bagasse (a by-product of sugar cane). The workers may also be affected by chronic infections which reduce their productivity. The legal framework for their protection is often inadequate. (Bener et al., 2012)

Industrial nurse has an important role in preventing industrial hazards. Her role includes determining workers health problems, identify industrial health hazards and dangerous conditions to health, plan and promote workers health by providing appropriate treatment. She participates in implementing a safety plan to prevent or minimize accidents and injuries that occur during daily activities. In educational

$P$ a g e 16

\section{Introduction:}

The workers working in the sugar industry are prone to face a number of stresses. Sugar mill employees would develop flulike symptoms several hours after reporting to work at the beginning of a new season or even after a free week end, repeated attacks causes fine scarring of the lungs and impaired breathing. Working condition in sugar industry includes cleanness, light, temperature (heat), ventilation, noise, vibration, physical energy required, length of work day, and irregularity of the work hours such as night shifts, physical hazards, exposure to possible industrial stressors and similar condition that directly or indirectly influence the worker's happiness, satisfaction, dissatisfaction at work. ( Nayakawadi,,2014)

Workers may be exposed to physical, chemical, and biological hazards at work that may lead to occupational illness. Hazardous substance exposure routes include dermal and inhalation exposure and ingestion,depending on the dose, route and duration of exposure, and chemical properties of the hazardous substance, exposure symptoms may range from mild discomfort to debilitating conditions or even death. Sudden exposure to large amounts of a toxic compound may lead to acute poisoning, causing life-threatening symptoms. Chronic exposure to even trace amounts of certain substances may cause serious health effects such as cancer or reproductive and teratogenic effects years after the exposure has ceased. Families of workers also can face risks from toxic substances brought home on contaminated work clothes or vehicles. (Biswas et al., 2016)

The injury of workers in sugar mills resulted in lack of safety measures, no proper training and education program, safety covers were not provided to the vibrating machines, Noise in the factory could lead occupational hearing loss while extreme temperatures from boilers and evaporators are likely serious burns and high levels of dehydration, poor ventilation and lighting during working hours, Other hazards include electric shocks, falls from tall buildings, burns from 
- Current complaint (dyspnea, chronic cough, chest pain, hearing disturbances, tinnitus, headache, blurring vision and others).

- Occupational history (previous work, absenteeism, exposure to accident, causes and its prevention).

Part 3- Health habit (smoking, shisha and others).

Part 4- Occupational health services

- Recreation services such as (sports, clubs and resorts).

- Health services such as (pre-placement examination, periodic medical examination and nursing services).

Tool II- Questionnaire to collect knowledge of workers about occupational health hazards such as (noise, dust, heat, light, ventilation and radiation) and how to prevent these hazards. Each correct answer took two scores, incomplete one took one score and the wrong answer or not known response took (zero). It contained 24 questions, so maximum total scores of knowledge were 48 . If scores $\leq 50 \%$ means poor knowledge (24 score), $51-70 \%$ means fair knowledge (25- 33.6 scores) and more than $70 \%$ means good knowledge ( $\geq 33.7$ scores)

Tool III- Self-reported practice questionnaire about using workers personal protective equipment and selfreported practice about most commonly first aid in the factory. Practice for personal protective equipment, each wear continuous took two scores, wear sometimes took one score and never wear took (zero). For first aid, know took two score and don't know took zero. It contained 51 questions, so maximum total scores of self-reported practice were 102 . If scores $\leq 50 \%$ means unsatisfactory (51 score), If scores $\geq$ $51 \%$ means satisfactory.

\section{Content Validity:}

The content validity of the data collection tool was examined by three experts who were affiliated to faculty of nursing and faculty of medicine Minia University at community health nursing department and public health / preventive medicine department. The tool was examined for content coverage, clarity, relevance, applicability, wording. Based on experts ' comments and recommendations; minor modifications had been made such as rephrasing and rearrangements of some sentences.

\section{Reliability:}

The internal consistency of the questionnaires was calculated using Cronbach's alpha coefficients. Test-retest was used. The Cronbach's alpha of the questionnaires were 0.833 and 0.798 indicate good reliability.

\section{Procedure}

- A review of the related literature which was covering various aspects of the risk factors has done, using different books, journals and web sites, to get acquainted with the research problem and to implement the study

- An official permission taken from the dean of the faculty for conducting the study.

- An official letter from the faculty of nursing was delivered to the director ( $\mathrm{s}$ ) of the intended study setting (sugar factory).

- Verbal informed consents were obtained from all the workers before the program enrollments. After that; a detailed explanation on study objectives was done.

- Data collection took about 6 months from (July to the end of December 2017). Three visits were program, she assesses worker's needs, develops appropriate educational program, by using formal and informal presentation, also she has a role in training workers to use preventive measures during working rencourages workers to use health services, evaluates effectiveness of workers response to nursing actions and control of environmental factors that cause a disease. (Bijayalaskhmi, 2017)

Aim of the Study (It is two-folded aim):

- To assess knowledge and self-reported practices of workers regarding occupational health hazards at sugar factory, Minia, Egypt.

- To assess the effect of health education program on knowledge and self-reported practices of workers regarding occupational health hazards at sugar factory, Minia, Egypt.

\section{Research hypothesis:}

1) The knowledge of workers regarding occupational health hazards will be improved after attending the proposed health education program.

2) The self- reported practice of workers regarding personal protective equipment and first aids will be improved after attending the proposed health education program.

\section{Subjects and Methods}

\section{Research Design:}

- Quasi experimental design (pre/posttest) was used for the current study.

\section{Research Setting:}

The present study was carried out in Minia sugarcane factory this is located in Abu Korkas district, 20 $\mathrm{km}$ south to Minia city and about $250 \mathrm{~km}$ south to Cairo, Egypt. It consists of eight departments namely; (industrial operations, squeezers, steam boilers, turbines, lime kiln, mechanical workshop, mechanical evacuation and sulfur furnace).

\section{Sample of the study:}

A purposeful sample with number of 130 workers were chosen out of the total 360 of the occupational workers at Abu Korkas sugarcane factory, after excluding engineers, technicians, supervisors and papers work and choose the most important hazards in the factory, namely (lime kiln, steam boilers, industrial operations and sulfur furnace ).

\section{Study Tool:}

Tool I- Structured interview questionnaire was constructed by the researcher after reviewing the relevant literature and recent scientific articles; this tool is consisted of four parts:

Part 1- Sociodemographic characteristics such as (name, age, income, residence, education level, marital status and years of work experience).

Part 2- Health history

- Past health history (diabetes, hypertension, cardiovascular disease, liver disease, hearing loss and others). 
program were given to each learner immediately after the pre-test.

- At the beginning of each session; the objective of the session explained. Also Feedback was done about the previous session and the content of the session were dealt using different ways of teaching. While the practical part of the teaching program was done for each session that corresponding with session contents

- Each session followed by a summary of essential points.

- At the end of program sessions, data were immediately collected using the study tool as a posttest

\section{Pilot study}

To assess the clarity, reliability and applicability of the study tools which was used in the study for data collection; a pilot study was conducted on $10 \%$ of the sample. The results of the pilot study was helped in the necessary modifications of the tools in which omission of unneeded or repeated questions, adding missed questions will be done.

\section{Statistical Analysis}

Statistical package for the social science SPSS version 21 was used for statistical analysis of data, as it contains the test of significance given in standard statistical books. Collected data was summarized and tabulated.

\section{Ethical consideration}

Informed verbal consent will be obtained from workers to be included in the study. It was included full explanation of the sheet, rights for privacy, confidentiality and rights to withdraw at any time. conducted to the factory every week. The data of the questionnaires were collected by the researcher through personal interviewing. The visit took about 6 hours in the morning shift. Each questionnaire took about 25-30 minutes. The average number of interviewed was 7-8 workers / day. During the interview, each individual was assured that the information obtained was confidential and used only for the purpose of the study. Moreover, each worker was asked by the researcher about using safety measures during work in addition to assess selfreported practice of workers about most common first aids in the factory.

- The program lasted for 6 months; the study started at the beginning of September 2016, and was completed by the end of February 2017.

- The health education program was implemented to the workers users in terms of sessions. Teaching continued for 6 months to complete the program content from (May to the end of October). The total numbers of sessions were $13 \quad(7$ sessions for knowledge and 6 sessions for self-reported practice (PPE and first aid). Health educational program was implemented to the worker who's divided into subgroups and before beginning of the first session, an orientation to the program and its purpose of the study were done .Each session started by a summary about what was given during the previous session and the objectives of the new topics.

- The studied workers divided into 10 groups, each group consisted of 13 workers and the researcher applied the program for each group on separate time and attended 13 sessions and duration of each session from one to two hours. Handouts of the

\section{Results}

Table (1) Frequency distribution of studied sugarcane workers regarding socio-demographic characteristics in Abokorkas sugarcane factory, $(n=130)$.

\begin{tabular}{|c|c|c|}
\hline Socio-demographic characteristics & No. & $\%$ \\
\hline \multicolumn{3}{|l|}{ Age/ year } \\
\hline $20-\leq 30$ & 11 & 8.5 \\
\hline $30-\leq 40$ & 29 & 22.3 \\
\hline $40-\leq 50$ & 49 & 37.7 \\
\hline $50-\leq 59$ & 41 & 31.5 \\
\hline Mean \pm SD & \multicolumn{2}{|c|}{$44.7 \pm 8.7$ years } \\
\hline \multicolumn{3}{|l|}{ Income / L.E } \\
\hline$>1000$ & 5 & 3.8 \\
\hline $1000->2000$ & 90 & 69.2 \\
\hline $2000->3000$ & 31 & 23.8 \\
\hline $3000-4000$ & 4 & 3.1 \\
\hline Mean \pm SD & \multicolumn{2}{|c|}{$1299 \pm 523.1$ L.E } \\
\hline Residence & & \\
\hline Rural & 76 & 58.5 \\
\hline Urban & 54 & 41.5 \\
\hline \multicolumn{3}{|l|}{ Educational level } \\
\hline Illiterate & 27 & 20.8 \\
\hline Read and write & 5 & 3.8 \\
\hline Primary education & 13 & 10.0 \\
\hline Secondary education & 80 & 61.5 \\
\hline Technical education & 3 & 2.3 \\
\hline - $\quad$ University education & 2 & 1.5 \\
\hline Years of work experience & & \\
\hline
\end{tabular}




\begin{tabular}{|ll|c|c|}
\hline$\bullet$ & 2 & 1.5 \\
\hline$\bullet$ & $5-\leq 10$ & 36 & 27.7 \\
\hline$\bullet$ & $10-\leq 15$ & 14 & 10.8 \\
\hline$\bullet$ & $15-\leq 20$ & 30 & 23.1 \\
\hline$\bullet$ & 48 & 36.9 \\
\hline & Mean \pm SD & $13.4 \pm 6.2$ years \\
\hline
\end{tabular}

Table (1) shows that, $37.7 \%$ of the workers were in the age group from $40-\leq 50$ years and $31.5 \%$ aged from $50-\leq 59$ years, while only $8.5 \%$ aged from 20 to less than 30 years with mean age of $44.7 \pm 8.7$ years. Regarding monthly income, $69.2 \%$ of the sample gets 1000 - > 2000 pounds, while only 3.1\% ranged from 3000-4000 pounds. Concerning to residence, 58.5\% live in rural area. As regard to level of education, $61.5 \%$ were secondary education and $20.8 \%$ were illiterate. Regarding years of work experience, $36.9 \%$ were ranged from $20-24$ years, while only $1.5 \%$ was less than 5 years.

Table (2) Relation between pre and post health educational program regarding worker's knowledge scores, (n=130).

\begin{tabular}{|c|c|c|c|c|c|}
\hline \multirow{2}{*}{\multicolumn{2}{|c|}{ Knowledge }} & \multicolumn{2}{|c|}{$\mathrm{X} \pm \mathrm{SD}$} & \multirow[t]{2}{*}{$\mathrm{t}$ - test } & \multirow[t]{2}{*}{$P$ - value } \\
\hline & & Pre & Post & & \\
\hline$\bullet$ & General knowledge & $0.4 \pm 1.0$ & $3.0 \pm 1.3$ & 17.602 & $.0001 * *$ \\
\hline$\bullet$ & Noise & $1.6 \pm .8$ & $2.6 \pm .9$ & 10.353 & $.0001 * *$ \\
\hline$\bullet$ & Heat & $1.6 \pm 1.7$ & $4.4 \pm .8$ & 18.539 & $.0001 * *$ \\
\hline$\bullet$ & Dust & $3.2 \pm 1.4$ & $4.1 \pm .3$ & 7.020 & $.0001 * *$ \\
\hline$\bullet$ & Bagassosis & $.7 \pm 1.4$ & $4.2 \pm 1.2$ & 21.969 & $.0001 * *$ \\
\hline$\bullet$ & Radiation & $1.7 \pm 1.7$ & $4.1 \pm .7$ & 14.570 & $.0001 * *$ \\
\hline$\bullet$ & Ventilation & $1.2 \pm .8$ & $1.4 \pm .6$ & 2.112 & $.04 *$ \\
\hline$\bullet$ & Lighting & $1.3 \pm .8$ & $2.0 \pm .4$ & 9.088 & $.0001 * *$ \\
\hline$\bullet$ & Total knowledge scores & $12.6 \pm 7.2$ & $45.4 \pm 11 . .3$ & 27.887 & $.0001 * *$ \\
\hline
\end{tabular}

** Statistically significant at $\mathrm{P}-$ value $\leq .01$

Table (2) reveals that there are highly statistically significant differences between pretest and posttest regarding workers knowledge, while there is a significant difference in knowledge of ventilation $(\mathrm{P}=.04)$.

Table (3): Relation between pre and post health educational program regarding using the personal protective equipment's continuously, $(n=130):-$

\begin{tabular}{|l|c|c|c|c|c|c|}
\hline \multirow{2}{*}{ PPE } & \multicolumn{2}{c|}{ Pre } & \multicolumn{2}{c|}{ Post } & \multirow{2}{*}{$\mathrm{X}^{2}$} & \multirow{2}{*}{ P - value } \\
\cline { 2 - 7 } & No. & $\%$ & No. & $\%$ & & \\
\hline Overall & 104 & 80.0 & 130 & 100.0 & $\mathrm{~F}=28.889$ & $.0001^{* *}$ \\
\hline Head cover & 12 & 9.2 & 103 & 79.2 & 130.264 & $.0001^{* *}$ \\
\hline Ear plug & 11 & 8.5 & 113 & 86.9 & 162.254 & $.0001^{* *}$ \\
\hline Face mask & 13 & 10.0 & 93 & 71.5 & 110.894 & $.0001^{* *}$ \\
\hline Gloves & 14 & 10.8 & 54 & 41.5 & 32.305 & $.0001^{* *}$ \\
\hline Rubber boot & 49 & 37.7 & 101 & 77.7 & 44.484 & $.0001^{* *}$ \\
\hline Muzzles & 0 & .0 & 128 & 98.5 & $\mathrm{~F}=257.333$ & $.0001^{* *}$ \\
\hline Glasses & 7 & 5.4 & 49 & 37.7 & 42.668 & $.0001^{* *}$ \\
\hline
\end{tabular}

** Statistically significant at $\mathrm{P}-$ value $\leq .01$

Table (3): illustrates that, $80 \%, 37.7 \%$ using overall and rubber boot in pretest respectively, while $100 \%, 77,7 \%$ in posttest respectively. There is highly significant difference between pre and posttest $\left(\mathrm{P}=.0001^{* *}\right)$

Table (4): Relation between pre and post health educational program among total studied sample regarding personal protective equipment's and first aids scores $(n=130)$ :-

\begin{tabular}{|c|c|c|c|c|c|}
\hline \multirow{2}{*}{\multicolumn{2}{|c|}{ First aid }} & \multicolumn{2}{|c|}{$\mathrm{X} \pm \mathrm{SD}$} & \multirow[t]{2}{*}{$\mathrm{t}-$ test } & \multirow[t]{2}{*}{$P$ - value } \\
\hline & & Pre & Post & & \\
\hline$\bullet$ & PPE & $6.7 \pm 2.2$ & $13.4 \pm 2.2$ & 24.436 & $.0001 * *$ \\
\hline$\bullet$ & Fracture & $2.2 \pm 1.2$ & $7.0 \pm 2.3$ & 21.255 & $.0001 * *$ \\
\hline$\bullet$ & Burn & $1.9 \pm 1.1$ & $6.7 \pm 2.1$ & 22.368 & $.0001 * *$ \\
\hline$\bullet$ & Foreign body & $1.9 \pm 1.2$ & $6.4 \pm 2.4$ & 19.062 & $.0001 * *$ \\
\hline$\bullet$ & Epistaxis & $1.5 \pm 1.2$ & $7.9 \pm 2.8$ & 23.581 & $.0001 * *$ \\
\hline$\bullet$ & Wound & $2.2 \pm 1.3$ & $5.1 \pm 2.1$ & 16.487 & $.0001 * *$ \\
\hline$\bullet$ & Fainting & $1.2 \pm 1.2$ & $5.1 \pm 2.1$ & 18.140 & $.0001 * *$ \\
\hline
\end{tabular}

** Statistically significant at $\mathrm{P}-$ value $\leq .01$

Table (4): Indicates that shows that there is highly statistically differences between pre and posttest regarding workers self-reported practice of personal protective equipment's and first aids. 
Minia Scientific Nursing Journal (Print) (ISSN 2537-012X) Vol. (4) No. (1) June 2019

Table (5): Relationship between pre and post health educational program regarding total studied sample knowledge and self-reported practices $(\mathrm{n}=130)$ :-

\begin{tabular}{|c|c|c|c|c|c|c|}
\hline \multirow[t]{2}{*}{ Items } & \multicolumn{2}{|c|}{ Pre } & \multicolumn{2}{|c|}{ Post } & \multirow{2}{*}{$\begin{array}{c}\text { Fisher exact } \\
\text { test }\end{array}$} & \multirow[t]{2}{*}{$\mathrm{P}-$ value } \\
\hline & No & $\%$ & $\mathrm{~N}$ & $\%$ & & \\
\hline \multicolumn{7}{|l|}{ Total practice } \\
\hline Unsatisfactory (less than $50 \%$ ) $\leq 51$ & 130 & 100.0 & 49 & 37.7 & \multirow[b]{2}{*}{117.654} & \multirow[b]{2}{*}{$.0001 * *$} \\
\hline Satisfactory practice $\geq 52$ & 0 & .0 & 81 & 62.3 & & \\
\hline \multicolumn{7}{|l|}{ Total knowledge } \\
\hline Poor (less than $50 \%) \leq 24$ & 130 & 100.0 & 43 & 33.1 & \multirow{3}{*}{130.751} & \multirow{3}{*}{$.0001 * *$} \\
\hline Fair ( $51-70 \%) 25-33.6$ & 0 & .0 & 82 & 63.1 & & \\
\hline - $\quad$ Good (more than $70 \%) \geq 33.7$ & 0 & .0 & 5 & 3.8 & & \\
\hline
\end{tabular}

** Statistically significant at $\mathrm{P}-$ value $\leq .01$

Table (5): Regarding total practice in pretest, all workers had unsatisfactory self-reported practice, while in posttest, $62.3 \%$ of workers had satisfactory self-reported practice. As regard to total knowledge in pretest, all workers had poor knowledge, while in posttest, $63.1 \%$ of workers had fair knowledge and only $3.8 \%$ had good knowledge. There is highly statistically significant difference between pre and posttest regarding workers knowledge and self-reported practice.

Table (6): Correlation between pre and post health educational program regarding total studied sample knowledge with self-reported practices $(n=130)$ :

\begin{tabular}{|c|c|c|c|c|c|}
\hline & \multirow{3}{*}{ Items } & \multicolumn{4}{|c|}{ Total knowledge score } \\
\hline & & \multicolumn{2}{|r|}{ Pre } & \multicolumn{2}{|c|}{ Post } \\
\hline & & $\mathrm{r}$ & $\mathrm{P}$-value & $\mathrm{r}$ & $\mathrm{P}$-value \\
\hline$\bullet$ & PPE & .153 & .082 & .304 & $.001 * *$ \\
\hline$\bullet$ & Fracture & .142 & .108 & .576 & $.0001 * *$ \\
\hline$\bullet$ & Burn & .032 & .720 & .485 & $.0001 * *$ \\
\hline - & Foreign body & .074 & .402 & .526 & $.0001 * *$ \\
\hline$\bullet$ & Epistaxis & .031 & .725 & .579 & $.0001 * *$ \\
\hline$\bullet$ & Wound & .066 & .456 & .402 & $.0001 * *$ \\
\hline$\bullet$ & Fainting & .016 & .859 & .502 & $.0001 * *$ \\
\hline $\begin{array}{l} \\
\text { score }\end{array}$ & Total self-reported practice & .083 & .350 & .617 & $.001 * *$ \\
\hline
\end{tabular}

** Statistically significant at $\mathrm{P}-$ value $\leq .01$

In table (6) illustrates that there were moderate positive correlation between workers' knowledge after health education program between their knowledge and total practice score, fracture, epistaxis, foreign body and fainting self-reported practice in which $\mathrm{r}=0.617,0.579,0.576,0.562$ and 0.502 respectively.

\section{Discussion}

Discussion is presented according to the aim of the study that to assess the effect of health education program on knowledge and practice of workers regarding occupational health hazards. Workers are exposed to serious health problems due to lack of knowledge and poor practices of using personal protective equipment. Therefore health education program regarding occupational health hazards and using personal protective equipment is vital for workers. Hence, the researcher keen to implement this study to evaluate the effect of health education program on knowledge and practice of workers regarding occupational health hazards.

Regarding age of workers in the study sample, more than one third with age 40 years with the mean age $44.7 \pm 8.7$. this consistent with (El-Khateb et al., 2011) who study some of the non-auditory effects of noise among exposed workers in abou-qurkas sugar factory, EL-Minia governorate, Egypt and found that all participants with ages ranging from $25-59$ years (mean age 42.4, S.D. \pm 8.0 ).

Regarding sex the present study show all workers were males. This consistent with (Hajiali et al, 2014) in Biston sugar production factory's occupational hearing and reported that all participants were males. However there are female members in factory but all of them in a way be involved with paperwork so not included in this study.

P a g e | 10
As regard to the education level, two third had secondary education, one fifth were illiterate and $10 \%$ had primary education. This result contradicted with (Berivan \& Al-Dosky,2015 ) who study noise level and annoyance of industrial factories in Duhok city and reported that 5.56\% no educational, less than one third primary school, one third intermediate, $5.56 \%$ technical and $2.22 \%$ university education.

Regarding place of residence, around two third of workers from rural area. This result consistent with (Aida, et al., 2014) who study Health Hazards of Solvents Exposure among Workers in Paint Industry and reported that majority of the workers resided in rural areas.

Regarding years of work experience, more than one third ranged from 20-24 years. this findings contradicted with (Islam et al., 2017) who study occupational health hazards and safety practices among the workers of tannery industry in Bangladesh and reported that more than half less than 5 year, one third from $5-10$ years and $14.2 \%$ was above 10 years.

Regarding previous work, the current study reveals that one third in architecture / construction. This results contradicted with (Bodin et al., 2016) who study intervention to reduce heat stress and improve efficiency among sugarcane workers in El Salvador and found that $44 \%$ in construction, $30 \%$ in cotton and 25 in mining. 
Regarding total knowledge, all workers had poor knowledge in pretest improved in posttest to more than two third had fair knowledge, one third had poor knowledge and only $3.8 \%$ had good knowledge. This result contradicted with (Shrimanti et al., 2016) who study occupational health: health promotion program to improve health workers in Tourah cement factory and reported that three quarter had average knowledge, less than one fifth had good knowledge and only $8 \%$ had poor knowledge in pretest improved in posttest to two third had average knowledge, more than one third had good knowledge and only $6 \%$ had poor knowledge except There is no significant difference between sociodemographic characteristics and knowledge post health education program .

Regarding types of personal protective equipment, majority of workers used overall continuously, more than three quarter used ear plug sometimes and vast majority never used muzzle in pretest improved in posttest, majority of workers used overall, muzzle, ear plug, head cover, rubber boot continuously and less than one fifth never used glasses, gloves and rubber boot. This disagree with (Esaiyas, Sanbata, \& Mekonnen, 2018) who study occupational health and safety related knowledge, attitude and practice among wood and metal workers in Hawassa, Ethiopia and reported that majority of workers never used ear plug, helmet ,two fifth used eye glasses continuously and one third used gloves and mask sometimes.

Regarding self-reported practice toward first aids, there is highly statistically difference between pre and posttest regarding workers self-reported practice of personal protective equipment's and first aids. All workers had unsatisfactory practice in pretest decreased to more than one third in posttest and after educational program two third had satisfactory practice. This result consistent with (Shafik \& Abd El-Mohsen, 2012) who study Occupational health: Health Promotion Program to Improve Health Workers in Tourah Cement Factory and reported that there were highly statistically significant differences between pre and post practices related to good, average and poor practice ( $\mathrm{P}$ $<0.000$ ). Majority of the studied sample had poor practice in case of contact between chemical materials and eye, entry of flying dust in the eye, ingestion of toxic materials and falling of persons from the height. However, good performance was not found among all workers in all seven cases of occupational hazards.

Regarding relationship between total knowledge and self-reported practice, there is highly statistically difference between pre and posttest regarding workers knowledge and self-reported practice. This consistent with (Adewale \& Adhuze, 2017) who study knowledge and practice of occupational hazard control among building construction workers in Lagos Metropolis, Nigeria and reported that there is a strong and significant positive relationship between knowledge and practice of hazard control.

\section{Conclusion}

- There was highly statistically significant improvement of worker's knowledge and selfreported practices regarding occupational health hazards after implementation of the health education program.

\section{Recommendations}

1) There is a need for a continuous planned educational and training program and offered on regular basis for workers to improve their knowledge and practice regarding occupational health hazards.

2) On-site training programs for workers have to be implemented to improve their working skills. Training programs should include safety measures and orientation regarding work hazards and how to avoid work related injuries as well as first aid measures.

3) Activate the role of occupational health nurse in the factory by facilitating periodic visits to workers to perform workplace assessment to ensure it doesn't affect workers health, develop \& implement the most suitable educational program to workers.

4) Further researches should be conducted to explore the health hazards in the field of occupational health.

\section{References}

1) Adewale,P.O., \& Olasunmbo, O., (Aug2017):Knowledge and practice of occupational hazard control among building construction workers in Lagos Mertopolis, Nigeria, International Journal of Advances in Engineering \& Technology;10(4): 512-522.

2) Ahmad, I., Sattar, A., Nawaz, A., (2016): Occupational health and safety in industries in developing world. Gomal J Med Sci; 14:223-8.

3) Aida, A., H., Elnagar,S.A., Ihab Mohammadi El Tayeb,I.M., \& Bolbol,S.A.,(2014): Health Hazards of Solvents Exposure among Workers in Paint Industry, Open Journal of Safety Science and Technology, 3:87-95.

4) Bener, A, Abdul Rahman, Y.S., Abdel Aleem, E.Y., \& Khalid, M.K., (2012): Trends and characteristics of injuries in the State of Qatar: hospital-based study. Int J Inj Contr Saf Promot; 19(4):368-72.

5) Berivan, H., Al-Dosky,M., (May. 2014):Noise level and annoyance of Industrial factories in Duhok city, IOSR Journal of Environmental Science, Toxicology and Food Technology (IOSR-JESTFT); 8 (5) : :1-08.

6) Bijayalaskhmi, D., (2017): A comprehensive textbook of community health nursing, 1st ed., Jaypee Brother Medical Publishers, New Delhi, Philadelphia, London, Panama, Pp:696-697.

7) Biswas,G., Bhattacharya,A. A., \& Bhattacharya, R., (2016): A review on the occupational health of sugar cane workers Gourab International Journal of Biomedical Research; 7(8): 568-570.

8) Bodin,T., García-Trabanino,R., Weiss,I., Jarquín,E., Glaser,J., Jakobsson,K., Lucas, R. A. I., Wesseling,C., Hogstedt,C., \& Wegman,D.H.,(2016): Intervention to reduce heat stress and improve efficiency among sugarcane workers in El Salvador: Phase 1, Occup Environ Med;73:409-416. doi:10.1136/oemed-2016-103555

9) El-Khateb, A.S., Refaat, T.M., El-Moselhy, E.A., El-Rehany, M.A., \& Zayet, H.H., (2011): some of the Non-auditory effects of noise among exposed workers in Abou-Qurkas Sugar factory, EL-Minia 
governorate, Egypt. Egyptian Journal of Occupational Medicine; 35 (2): 227-236.

10) Esaiyas,A., Sanbata,H., \& Mekonnen,Y., (2018):Occupational Health and safety related knowledge,Attitude and practice among wood and metal workers in Hawassa, Ethiopia, annual research \& review in biology;22(6): 1-9.

11) Hajiali, Y., Weisi, B., \& Hashemian,A.H., (2014): Complete Survey of Biston Sugar Production Factory's Occupational Hearing, Advances in Biological Research 8 (5): 187-190.

12) Hamza,M., (2016): Sugar Industry Struggles with Government's New Food Subsidy Reform Program, Sugar Annual 2015, USDA foreign Agriculture Service, p1-9.

13) Islam, R.,Shakhaoat, H., \& Abu Bakkar, S.,(2017):Occupational health hazards and safety practices among the workers of tannery industry in Bangladesh, J. Biol. Sci. 6(1): 13-22.
14) Nayakawadi,S.A., ( July 2014):Assessment of Respiratory Stress in Work Place Environment of Sugar Industry, Indian Journal of applied research, 4(7)pp:335-336.

15) Shafik,S.A., \& Abd ElMohsen,A.S.,(2012):Occupational health: Health Promotion Program to Improve Health Workers in Tourah Cement Factory. Journal of American Science; 8(3): 486-496. (ISSN: 1545-1003). http://www.americanscience.org.

16) Shrimanti, D. P., Avinash, H. S., Kakade,N.R., Katti,A. V., Vaishali, R.M., (2016):, A Study to assess knowledge on occupational health hazards among the workers of Jaggery factory with special emphasis to prepare health educational material in selected Jaggery factories at Kolhapur, India, international journal of innovative research \& development; 5(6):124-132. 